\title{
Matrix Management Approach and a Survey Research in the Industry
}

\author{
Asst. Prof. Dr. Ceren Gül Artuner (Beykent University, Turkey) \\ Prof. Dr. Erdoğan Taşkın (Beykent University, Turkey)
}

\begin{abstract}
This academic research aims to determine the approach of the employees in different organizations to the matrix management style. Although the practice of matrix management style is quite difficult and its implementation costs are high, the main reasons of its adoption by the managers are discussed. In this research, the facts of establishing effective and reliable communication with all of the employees in an enterprise, working as efficient teams, the interrelation among the teams, solving problems as a team as well as receiving education for conflict resolution and ensuring cooperation among people while maintaining the values of the enterprises are investigated. In addition, the attitude of the managers in the performance of important tasks towards prioritizing knowledge and competence rather than authority and line relationships, the establishment of an integral and equitable performance evaluation system, the existence of a consistent information flow and a multidimensional accounting are inquired. Besides, by the integration of the conflict management process into the planning process, the use of the appropriate planning software, and clearly defining the tasks with all the details and responsibilities involved, the building-up of needed connections to do the work and at the same time, which add value to the work, are evaluated.
\end{abstract}

\section{Introduction}

While the external environment of an enterprise is changing especially in the terms of competition and technology, its internal structure has to adapt to these changes. A huge, complex and international enterprise with a functional structure where the line relationships are defined traditionally and where the departments are organized in an interlinked manner as production management, finance, human relations, management information systems, research and development has experiences more difficulties to adapt to the external environment. Particularly, in the case of enterprises which have numerous projects and a wide range of products, the matrix organization structure is outstanding as the most suitable option for many years among the long existing organizational structures. Matrix structure is a form of departmentalization or organizational design in an enterprise. The recent evolutions in the means of communication, the introduction of sophisticated technologies and an increase in the practice of project management has reinforced the frequency of use and applications of matrix organization type (Dylon et al., 2016)

However, the most important challenges experienced in applying the matrix structure are the fact of reporting of an employee to more than one manager and the practice of cross working between different teams. As products are getting more complex and customers increase in number, most of the companies tend to refer to teamwork (Johnson and Geal, 2016; Kotler and Armstrong, 2016).

Contemporary communication means has transformed the companies in a drastic manner. The managers are taking advantage of the communication means more intensely during the planning, implementation and control activities. Matrix structure is providing efficiency during the exercise of management functions (Joyce, 1986; Gunn, 2013).

Acquiring knowledge of developing technologies is facilitating the economic struggle of a country. All of the large companies operating with restrained abilities and limited financial resources must ultimately benefit from the matrix organization structure in order to carry out production efficiently, to take advantage from specialization, to be distinguished from its competitors in the market, to augment its sales, to utilize efficient technologies, to adapt to the environment and to realize its goals and objectives (Kingdon, 1973; Erdoğan, 1997).

\section{The Importance of the Matrix Structure}

During the 2nd World War, the matrix structure was used for the first time in order to benefit from the experiences of talented engineers and to produce complex guns and war tools, but it cannot be a remedy for resolving all the problems concerning the contemporary organizations structure (Numerof and Abrams, 2002).

In the post war period, project management has been widely used in different industries like pharmaceutics, construction, naval construction and aeronautics all along with defense and spatial industries. The introduction of new production techniques and the adoption of new practices in various fields required the careful implementation of matrix structure in global enterprises in today's civilized world. In addition, matrix structure is commonly used in defense industry in Turkey (Pretorius and Taylor, 1986; Gunn, 2013; Baysak, 2016). 
In times of economic fluctuations where societal transformations were occurring and customers' expectations were shifting, the managers used the matrix organization structure as a flexible and dynamic mean to adapt to the ongoing changes (Shreiber and Rosenberg, 2015).

Matrix structure is not a classical organization type or old fashioned departmentalization style where the job description of all of the employees are strictly and clearly determined in advance (Peters, 1979).

This contemporary form could be adopted by the management with a fresh and different look to the departments, employees and the ongoing works in the company. The employees do not have to consider their tasks in a restricted manner squeezed in a predetermined organizational structure. Indeed, matrix structure requires every manager and employee to see his / her task from a broader point of view and to attach importance to the ultimate details while performing it (Kolodny, 1979).

In fact, the matrix structure is not only an organizational structure but also a managerial thinking system and consists of building shared values. It also means creating a common point of view among the employees, augmenting the workforces' efficiency and ensuring its efficient functioning, together with integrating the management's efforts and succeeding the needed change and transformation (Barlett and Ghoshal, 1990).

"In the fully developed large-scale global company, product or business, function, area and customer know-how are simultaneously focused on the organization's world-wide marketing objectives. This type of total competence is a matrix organization. Management's task in the matrix organization is to achieve an organizational balance that brings together different perspectives and skills to accomplish the organization's objectives" (Keegan and Green, 2013).

In mighty organizations with a considerable number of employees, producing on a big scale and targeting a variety of markets, rethinking to organize different departments like marketing communication, product management, production, data processing, research and development in an integrated matrix organizational structure would facilitate the accomplishment of goals of the company as a whole (Burton et al., 2015).

A company has to have some apparent skills in order to adopt and implement the matrix organization structure as a management concept in a successful manner. In the context of this research, the opinions of employees in different organizations concerning the level of the apparent institutional skills required for a successful implementation of matrix structure is asked. Undoubtedly, other institutional properties are also needed for the success of a matrix structure application in the practice. However, this research is analyzing the traits or particularities of companies who adopted a matrix structure with reference to sixteen questions. Matrix structure does not mean solely a change in the organizational structure, but it also involves a change of paradigm at every managerial level. In order to ensure this change, favorable conditions for learning and training opportunities must be created for the employees. People who would carry these efforts in the company, especially those who are in key positions and the managers supposed to bring about this change must have excellent communication skills. The thoughts and the actions as well as the performance of this workforce must traverse the company's actual boundaries (Galbraith, 1971; Galbraith, 2009; Gunn, 2013).

\section{The Problems Encountered and Their Solutions}

Contemporary organizations have to cope first with a lot of problems in order to accomplish their goals and to survive. The nature of the products and services introduced to the market are getting more and more complex. In addition to that, customers are asking for more integrated services. There is a considerable constraint on minimizing the costs. However, the talented and experienced employees are hard to find. Most of the time, the management reveals to be inadequate in satisfying the employees expectations, in establishing a flawless communication, in giving an account of its actions and in making powerful decisions. In such a case, a matrix structure may offer new solutions to the above mentioned problems by handling them more carefully (Numerof and Abrams, 2002).

If there is growing conflict between the teams and the team leaders, a need for a more flexible teamwork, the work performed by the employees doesn't serve to the realization of the main objectives of the organization, the managers can't manage their subordinates without referring to their authorities, there exists general optimization problems throughout the organization, the resources are not exploited at the optimum level, the organization becomes more complex and gets hard to manage, the goals must be adjusted more quickly and more simply, the planned projects take more time to be implemented strategically and the production time gets longer, rumors and blaming others becomes familiar among the employees, some employees are fired but it doesn't contribute to the solving of the problems, there's only a few persons who are doing their best while the others are reluctant for working, there's no innovation, the organization may need to be restructured in an effective manner. Briefly, if the contemporary organizations' managers are willing to cope with these problems in an efficient and effective way, they have to learn about matrix structure and implement it. In an integrated manner with the global economic system, the companies whose targeted customers are not loyal to any product nor service are trying to adapt themselves to a continuously changing environment. They may reshape their organizations according to the matrix 
structure in order to realize their strategies, to ensure a powerful leadership, to take profit from teamwork, to reach the top, to change the game's rules and to achieve their competitive transformation (Martin, 2013).

Needless to say that the matrix organization type is not a remedy for all the diseases. There is a need in the organizations for a more creative managerial view, which detects and identifies the problems from a broader perspective instead of criticizing all. The hiring of talented workforce to the company, their training, leading, assigning them in appropriate teams and projects could grow the matrix organization's success. In the enterprise, all the managers perform their most key tasks based on knowledge and competence, not according to their line authority. The power rests on knowledge and competence in the company. The high-ranking persons in the company are accustomed to impress the employees by practice without referring to their line authorities. A complete and equitable performance appraisal is put into practice trough the organization. The company spares time to measure all the different performance types, both quantitative and qualitative. The workforce and the management resolves effectively the arising problems together. The companies are developing the principles and values, which would encourage the cooperative problem solving. The workforce reacts to the arising problems as: "How can I contribute to the solution of this problem?" Instead of "That doesn't concern me!" In an effective matrix structure, it is not acceptable to blame anyone for the coming out problems. The management follows the company's conduct by consulting the employees in the whole organization regularly. Like every organizational structure, matrix management style has also its weaknesses and its strengths. Planning management and human resources department have to assume this responsibility. Especially, people who are reporting to more than one superior must be followed closely. People who has something to say must be heard in private sessions or they must have to be part of focus groups. It is also proven by a research that, for the sake of the company's future, the following of such precautions is extremely important (Galbraith, 2009).

\section{Materials and Methods}

The aim of this academic study is to determine the matrix organization type management perception of the managers. Throughout the research, we have referred to the capabilities that a company needs to successfully execute a matrix organization. The discussion of these capabilities are spread throughout the survey. The survey can test how effective the leaders believe the company is at executing the capability. The following scale are the competencies and capabilities necessary for executing a matrix, and these are that we research for in effective matrix organization under twelve headings:

1. The company possesses high social capital or no silos. As the elements of a reliable workforce, a high level of communication is established with all the employees. As the most important feature of the matrix organization, formal or informal communication with every employee working for the company must be established in a reliable and straightforward manner (Burns and Wholey, 1993).

2. All the workforce work within the boundaries of the enterprise as effective teams. Matrix structure is naturally based on teamwork. The team players and the leaders identify the problems, discuss on them and work together to solve them. That is why the teams are working in a cross-borders, cross-companies and cross-functions manner (Davis and Lawrence, 1978).

3. Every team works in an interlinked manner with the others in the company. The teams operating in a matrix structure are linked to the others in different ways and in various domains. The planning process is driven with the team and the estimations or the prospective problems are communicated to the management (Kinor and Francis, 2016).

4. The workforce had a training as a team on problem solving and conflict management skills. All the teams within the matrix structure face conflicts and disparities. In order to resolve those conflicts and to perform better, the workforce needs similar skills and common processes (Spencer and Cox, 1995).

5. The most important task of the managers is to ensure the habitual cooperation and to protect the values. The company chooses the employees who would succeed in a matrix structure, hires them, train them, coaches them and promotes them (Brown and Agnew, 1982; Galbraith, 2009).

6. Continuous information flow and multidimensional accounting practices exist in order to measure the performance in the organization. The company can measure all of the dimensions of the matrix functioning with profit-loss charts and can use them to take decisions. All those data are made accessible to the teams planning and implementing the work to be done (Galbraith, 2009).

7. The planning process is at the same time a conflict resolution process. Planning is also an organizational process aiming to resolve the existing conflicts (Galbraith, 2009).

8. The company's management uses the appropriate planning software to effect the necessary alignments for doing the work. The teams using multidimensional accounting system do the planning which ends by the definition of goals and objectives (Galbraith, 2009).

9. Leaders build relationships required to do the work and which add value to the workforce. Leaders organize a variety of activities, work the employees alternately and arrange training activities, which 
create value. Developing the cross-relationships effectively in its own unit is evaluated positively in the performance appraisal of a manager (Galbraith, 2009).

10. Leadership means communicating entirely to the employees their tasks, responsibilities and the required details to do the work. In order to preserve the matrix structure, the manager should give an account of important details concerning the responsibilities and tasks designated to the workforce. Within the context of a team, people to do the work, to implement the decisions, to give an account of the results of a decision or of an activity as well as people to consult or to provide with knowledge must be predefined elaborately (Galbraith, 2009).

11. The actual work processes and the problems are defined altogether in the enterprise. The problems are defined and solved cooperatively. The different work processes or prospective problems are brought to the leadership team. Most of the time, a planning process gather them and fixes the priorities (Larson and Gobeli, 1987).

12. A strong leadership team sets a good example for all of the employees. The leadership in the matrix organization, particularly the top management looks like a team sport. Substantial difficulties encountered during the performance of a work is transmitted to the top management. The top management must set a good example for the employees in dealing with tricky situations and resolving the embarrassing problems (Bazigos and Harter, 2015; Sy and d'Annunzio, 2005).

Orientation Main Category: (1) The company possesses high social capital or no silos. (2) People work effectively in teams across organizational boundaries. (3) People are trained in the skills of team problem solving and conflict management.

Communication Main Category: (4) The teams are interconnected. (5) Managers in the key roles are naturally collaborative, and they live in values. (6) The leadership builds networks and values networkers. (7) The leadership ensures that roles, responsibilities, and interfaces are clearly defined. (8) Joint escalation processes are known and used intelligently. (9) A strong leadership team sets the example.

Coordination Main Category: (10) There are multidimensional accounting systems to track multidimensional performance. (11) The planning process is also the conflict resolution process. (12) There is a spreadsheet planning process that aligns the goals of the dimensions of the matrix.

These properties are further classified under three categories, which will form our dependent variables in the context of this research: The communication, orientation and coordination levels perceived by the managers. The independent variables are classified under four headings: The managerial position, the age of the manager, the size of the organization, and the educational level of the managers. Briefly, the variability in the perception of the managers towards the matrix organization structure regarding twelve competency and capability features organized under three main groups required to form the matrix organization structure are measured using one-way variance analysis ANOVA. The one-way ANOVA is considered a robust test against the normality assumption. This means that it tolerates violations to its normality assumption rather well (McClave, Sincich, 2006).

Within the context of this research, first, one sample T-Test is applied. The test value is obtained as " 1 ". The P (significance) value is " 0 ". $<0.05$ is the rejection area of the H0 hypothesis. So, the H0 hypothesis is rejected and H1 hypothesis is accepted.

H0 : The managers cannot perceive matrix organization type management properties in the enterprises they are working in.

H1 : The managers can perceive matrix organization type management properties in the enterprises they are working in.

In all the companies we have examined, the perception level regarding the matrix organization type management of the managers are similar.

\begin{tabular}{|c|c|c|c|c|c|}
\hline & Sum of Squares & Grding df & Mean Square & F & Sig. \\
\hline Between Groups & 1,697 & 4 &, 424 &, 417 &, 796 \\
\hline Within Groups & 131,303 & 129 & 1,018 & & \\
\hline Total & 133,000 & 133 & & & \\
\hline
\end{tabular}

Table 1. Relationship between Orientation and Managerial Position

The relationship between orientation variable and managerial position is insignificant $(0.796>0.05)$. The managerial position of the manager does not affect the orientation in the enterprise. 


\begin{tabular}{|l|c|c|c|c|c|}
\hline & Sum of Squares & df & Mean Square & F & Sig. \\
\hline Between Groups & 5,186 & 3 & 1,729 & 1,758 &, 158 \\
\hline Within Groups & 127,814 & 130 &, 983 & & \\
\hline Total & 133,000 & 133 & & & \\
\hline
\end{tabular}

Table 2. Relationship between Orientation and Educational Level

The relationship between orientation variable and educational level is insignificant $(0.158>0.05)$. The educational level of the manager does not affect the orientation in the enterprise.

\begin{tabular}{|l|c|c|c|c|c|}
\hline & Sum of Squares & df & Mean Square & F & Sig. \\
\hline Between Groups &, 917 & 2 &, 458 &, 455 &, 636 \\
\hline Within Groups & 132,083 & 131 & 1,008 & & \\
\hline Total & 133,000 & 133 & & & \\
\hline
\end{tabular}

Table 3. Relationship between Orientation and Age

The relationship between orientation and the age of the manager is insignificant $(0.636>0.05)$. The age of the manager does not affect the orientation in the enterprise.

\begin{tabular}{|l|c|c|c|c|c|}
\hline & Sum of Squares & df & Mean Square & F & Sig. \\
\hline Between Groups &, 963 & 3 &, 321 &, 316 &, 814 \\
\hline Within Groups & 132,037 & 130 & 1,016 & & \\
\hline Total & 133,000 & 133 & & & \\
\hline
\end{tabular}

Table 4. Relationship between Orientation and the Size of the Organization

The relationship between orientation and the size of the organization is insignificant $(0.814>0.05)$. The size of the organization does not affect the orientation in the enterprise.

\begin{tabular}{|l|c|c|c|c|c|}
\hline & Sum of Squares & df & Mean Square & F & Sig. \\
\hline Between Groups & 9,597 & 3 & 3,199 & 3,370 &, 021 \\
\hline Within Groups & 123,403 & 130 &, 949 & & \\
\hline Total & 133,000 & 133 & & & \\
\hline
\end{tabular}

Table 5. Relationship between Coordination and the Size of the Organization

The relationship between coordination and the size of the organization is significant $(0.021<0.05)$. When the organization's size is larger, there is more tendency towards a positive perception of coordination function in the enterprise.

\begin{tabular}{|l|c|c|c|c|c|}
\hline & Sum of Squares & df & Mean Square & F & Sig. \\
\hline Between Groups & 1,204 & 3 &, 401 &, 396 &, 756 \\
\hline Within Groups & 131,796 & 130 & 1,014 & & \\
\hline Total & 133,000 & 133 & & & \\
\hline
\end{tabular}

Table 6. Relationship between Coordination and the Educational Level of the Employee

The relationship between coordination and the educational level of the manager is insignificant $(0.756>0.05)$. The educational level of the manager does not affect the coordination in the enterprise.

\begin{tabular}{|l|c|c|c|c|c|}
\hline & Sum of Squares & df & Mean Square & F & Sig. \\
\hline Between Groups & 1,687 & 4 &, 422 &, 414 &, 798 \\
\hline Within Groups & 131,313 & 129 & 1,018 & & \\
\hline Total & 133,000 & 133 & & & \\
\hline
\end{tabular}

Table 7. Relationship between Coordination and Managerial Position

The relationship between coordination and managerial position is insignificant $(0.798>0.05)$. The managerial position of the manager does not affect the coordination in the enterprise. 


\begin{tabular}{|l|c|c|c|c|c|}
\hline & Sum of Squares & df & Mean Square & F & Sig. \\
\hline Between Groups & 2,444 & 2 & 1,222 & 1,226 &, 297 \\
\hline Within Groups & 130,556 & 131 &, 997 & & \\
\hline Total & 133,000 & 133 & & & \\
\hline
\end{tabular}

Table 8. Relationship between Coordination and Age

The relationship between coordination and the age of the manager is insignificant $(0.297>0.05)$. The age of the manager does not affect the coordination in the enterprise.

\begin{tabular}{|l|c|c|c|c|c|}
\hline & Sum of Squares & df & Mean Square & F & Sig. \\
\hline Between Groups & 1,046 & 3 &, 349 &, 343 &, 794 \\
\hline Within Groups & 131,954 & 130 & 1,015 & & \\
\hline Total & 133,000 & 133 & & & \\
\hline
\end{tabular}

Table 9. Relationship between Communication and the Size of the Organization

The relationship between communication and the size of the organization is insignificant $(0.794>0.05)$. The size of the organization does not affect the communication in the enterprise.

\begin{tabular}{|l|c|c|c|c|c|}
\hline & Sum of Squares & df & Mean Square & F & Sig. \\
\hline Between Groups & 1,906 & 3 &, 635 &, 630 &, 597 \\
\hline Within Groups & 131,094 & 130 & 1,008 & & \\
\hline Total & 133,000 & 133 & & & \\
\hline
\end{tabular}

Table 10. Relationship between Communication and the Educational Level of the Employee

The relationship between communication and the educational level of the manager is insignificant $(0.597>$ 0.05). The educational level of the manager does not affect the communication in the enterprise.

\begin{tabular}{|l|c|c|c|c|c|}
\hline & Sum of Squares & df & Mean Square & F & Sig. \\
\hline Between Groups & 5,089 & 4 & 1,272 & 1,283 &, 280 \\
\hline Within Groups & 127,911 & 129 &, 992 & & \\
\hline Total & 133,000 & 133 & & & \\
\hline
\end{tabular}

Table 11. Relationship between Communication and the Managerial Position of the Employee

The relationship between communication and the managerial position of the manager is insignificant $(0.280>$ 0.05). The managerial position of the manager does not affect the communication in the organization.

\begin{tabular}{|l|c|c|c|c|c|}
\hline & Sum of Squares & df & Mean Square & F & Sig. \\
\hline Between Groups & 5,645 & 2 & 2,822 & 2,903 &, 058 \\
\hline Within Groups & 127,355 & 131 &, 972 & & \\
\hline Total & 133,000 & 133 & & & \\
\hline
\end{tabular}

Table 12. Relationship between Communication and Age

The relationship between communication and the age of the manager is significant $(0.058=0.05)$. As the manager grows older and gets more experienced, he / she perceives more positively the communication in the enterprise.

\begin{tabular}{|l|c|c|c|c|}
\hline & Age & $\begin{array}{c}\text { Managerial } \\
\text { Position }\end{array}$ & Educational Level & $\begin{array}{c}\text { Size of The } \\
\text { Organization }\end{array}$ \\
\hline Communication & Positive Correlation & Irrelevant & Irrelevant & Irrelevant \\
\hline Coordination & Irrelevant & Irrelevant & Irrelevant & $\begin{array}{c}\text { Positive } \\
\text { Correlation }\end{array}$ \\
\hline Orientation & Irrelevant & Irrelevant & Irrelevant & Irrelevant \\
\hline
\end{tabular}

Table 13. One-Way ANOVA Comparisons 


\section{Discussion}

This survey is effectuated with the managers of companies operating in different sectors. In sum, 134 managers have participated to this research. Therefore, in the future, this research has to be reconducted with the managers of companies operating in a specific industry's context. Consequently, the data obtained from this new study could be compared with the results of the present research.

\section{Conclusion}

As the organization gets larger, the age of the manager is affecting more the inclination towards the matrix organization management type.

There are three sub-dimensions identified. (1) The communication function. (2) The coordination function. (3) The orientation function.

According to the factor analysis, we defined the Cronbach - Alpha Coefficient for each of these sub-dimensions as follows: (1) Communication: 0.815 (2) Coordination: 0.678 (3) Orientation: 0.618.

Tukey HSD and Bonferroni post-hoc tests are also applied to clarify the relationship between the size of the organization and the perceived coordination function. According to the Bonferroni test, it can be inferred that in local organizations, the perceived coordination is weaker than the regional organizations (the $p$ value (significance) is 0.035 in local organizations, while it is 1,000 in regional ones).

It has been recorded a $10 \%$ difference between national and regional organizations: It is estimated that the perceived coordination is $10 \%$ weaker in national organizations than in the regional ones. Besides, the perceived coordination in regional organizations is $5 \%$ weaker than in local organizations.

So we can state that the perceived coordination level is as follows according to the size of the organizations: Local $>$ Regional $>$ National.

All along with that, according to the Bonferroni test applied to identify the age of the manager and perceived communication level variables, we have assessed that, between the managers who are 22-26 years old and the managers who are 27-35 years old, there is a $10 \%$ increase in the perception level, while between the managers who are 22-26 years old and the managers who are 36-49 years old, there is an increase of $5 \%$ in the perception level.

Thus, we can assume that, as the managerial experience increases, an increase in the tendency towards the matrix organization type management is recorded.

Furthermore, the tendency towards simultaneous treatment of work processes to be defined and problems to be solved, the cooperation degree of the management and the workforce in solving the problems all along with the follow-up of the company's actual position by getting continuous feedback from the employees contacting them regularly and leading them by giving examples are observed and measured.

Additionally, the opinion of the employees concerning the change in the management view, their assessments and evaluations are taken into consideration.

\section{Acknowledgements}

The authors would like to thank Hakan Bal, Bahattin Sinsoysal, and Barış Batuhan Geçit for help with the tables.

\section{References}

- Amy Kates and Greg Kesler, 2013. “Activate the Matrix for Integration”, People and Strategy, Volume 36 Issue 1, pp.6-7.

- Barry Johnson and Mandy Geal, January 2016. “Matrix Management”, Training Journal, pp.28-31.

- Brent Durbin, 23 Sep. 2016. “Matrix Organization”, Britannica Online, https://global.britannica.com.

- Christopher A. Barlett and Sumantra Ghoshal, July-August 1990. "Matrix Management: Not a Structure, a Frame of Mind”, Harvard Business Review, Volume 68 Issue 4, pp. 138-145.

- Donald Ralph Kingdon, 1973. Matrix Organization Managing Information Technologies; Organizations, People, Society, Tavistock Publications, London.

- Dylon Moodley and Margie Sutherland, Pieter Pretorius, 2016. "Comparing the Power and Influence of Functional Managers with that of Project Managers in Matrlx Organisations: the Challenge in Duality of Command", South African Journal of Economic and Management Sciences, Volume 19 Issue 1, pp.103117.

- Erik W. Larson and David H. Gobeli, Summer, 1987. "Matrix Management: Contradictions and Insights", California Management Review, Volume 29 Issue 4, pp.126-138. 
- $\quad$ F. I. H. Pretorius, and R. G. Taylor, September 1986. “Conflict and Individual Coping Behaviour in Informal Matrix Organizations within the Construction Industry”, Construction Management and Economics, Volume 4 Issue 2, pp.87-90.

- Feridun Baysak, “SASAD”, 29 September 2016. Interview with General Secretary of Defense and Aviation Industry Manufacturers Association, Ankara.

- Harvey F. Kolodny, October 1979. “Evolution to a Matrix Organization”, Academy of Management Review. Volume 4 Issue 4, pp.543-553.

- James T. McClave and Terry Sincich, 2006. Statistics, Tenth International Edition, Pearson Prentice Hall, England.

- Jay R. Galbraith, 2009. Designing Matrix Organizations That Actually Work: How IBM, Procter \& Gamble, and Others Design for Success, The Jossey-Bass Business and Management Series, San Francisco.

- Jay R. Galbraith, February 1971. “Matrix Organization Designs”, Business Horizons, Volume 14 Issue 1, pp.29-40.

- John L. Brown and Neil McK. Agnew, November/December 1982. "The Balance of Power in a Matrix Structure”, Business Horizons, Volume 25 Issue 6, pp.51-54.

- Lawton Burns and Douglas Wholey, February 1993. "Adoption and Abandonment of Matrix Management Programs: Effects of Organizational Characteristics and Interorganizational Networks”, Academy of Management Journal, Volume 36 Issue 1, pp.106-138.

- Len Kinor and Ed Francis, February 2016, “Navigating Matrix Management”, Leadership Excellence Essentials, Volume 33 Issue 2, pp.23-24.

- $\quad$ M. S. Spencer and J. F. Cox, May 1995. “An Analysis of the Product-Process Matrix and Repetitive Manufacturing”, International Journal of Production Research, Volume 33 Issue 5, pp.1275-1294.

- Michael Bazigos, and James Harter, 2015. “Revisiting the Matrix Organization”, McKinsey Quarterly, Issue 4, pp.8-13.

- Nick Shreiber and Mike Rosenberg, 2015. “How to Make the Matrix Work”, IESE Insight, 3rd Quarter, Issue 26, pp.46-53.

- $\quad$ Paula K. Martin, 2013. Matrix Management Reinvented- The New Game in Town, International Matrix Management Publishing, USA.

- $\quad$ Peter F. Drucker, 1973. Management: Tasks, Responsibilities, Practices, Harper and Row Publishing, New York.

- $\quad$ Richard Burton and M.Børge Obel, Dorthe Døjbak Håkonsson, 2015, "How to Get the Matrix Organization to Work”, Journal of Organization Design, Volume 4 Issue 3, pp.37-45.

- Richard Lepsinger, “Influencing In A Team”, February 2016. Leadership Excellence Essentials, Volume 33 Issue 2, pp.28-29.

- Rita E. Numerof and Michael N. Abrams, Summer 2002. “Matrix Management: Recipe for Chaos?”, Directors and Boards, Volume 26 Issue 4, pp.42-45.

- $\quad$ Ronald A. Gunn, 2013.Matrix Management Success-Method Not Magic, Infinity Publishing, USA.

- Philip Kotler and Gary Armstrong, Principles of Marketing, Sixteenth Global Edition, Pearson Education, England, 2016.

- Stanley M. Davis and Paul R. Lawrence, May/June, 1978. "Problems of Matrix Organizations”, Harvard Business Review, Volume 56 Issue 3, pp. 131-142.

- Thomas Sy and Laura Sue D'Annunzio, 2005. "Challenges and Strategies of Matrix Organizations: TopLevel and Mid-Level Managers' Perspectives”, Human Resource Planning, Volume 28 Issue 1, pp.39-48.

- Tom Peters, 20 September 2016. “Beyond the Matrix Organization”, McKinsey Quarterly, Septemper 1979/ http://www.mckinsey.com.

- Warren J. Keegan and Mark C. Green, 2013.Global Marketing, Seventh Global Edition, Pearson, England.

- William F. Joyce, September 1986. “Matrix Organization: A Social Experiment”, Academy of Management Journal, Volume 29 Issue 3, pp.536-561. 